\title{
Biodiversity effects on nitrate concentrations in soil solution: a Bayesian model
}

\author{
Sophia Leimer $\cdot$ Christian Wirth • \\ Yvonne Oelmann · Wolfgang Wilcke
}

Received: 31 August 2012/Accepted: 17 September 2013/Published online: 14 October 2013

(C) Springer Science+Business Media Dordrecht 2013

\begin{abstract}
Ecosystems are faced with high rates of species loss which has consequences for their functions and services. To assess the effects of plant species diversity on the nitrogen $(\mathrm{N})$ cycle, we developed a model for monthly mean nitrate $\left(\mathrm{NO}_{3}\right.$ $\mathrm{N}$ ) concentrations in soil solution in $0-30 \mathrm{~cm}$ mineral soil depth using plant species and functional group richness and functional composition as drivers and assessing the effects of conversion of arable land to grassland, spatially heterogeneous soil properties, and climate. We used monthly mean $\mathrm{NO}_{3}-\mathrm{N}$ concentrations from 62 plots of a grassland plant diversity experiment from 2003 to 2006. Plant species richness (1-60) and functional group composition (1-4 functional groups: legumes, grasses, non-leguminous tall herbs, non-leguminous small herbs) were manipulated in a factorial design. Plant community composition,
\end{abstract}

Responsible Editor: Kathleen Lohse.

S. Leimer · W. Wilcke $(\square)$

Geographic Institute, University of Bern,

Hallerstrasse 12, 3012 Bern, Switzerland

e-mail: wolfgang.wilcke@giub.unibe.ch

C. Wirth

Institute of Biology, Special Botany and Functional

Biodiversity Research, University of Leipzig,

Johannisallee 21-23, 04103 Leipzig, Germany

Y. Oelmann

Geoecology, University of Tübingen, Rümelinstr. 19-23, 72070 Tübingen, Germany time since conversion from arable land to grassland, soil texture, and climate data (precipitation, soil moisture, air and soil temperature) were used to develop one general Bayesian multiple regression model for the 62 plots to allow an in-depth evaluation using the experimental design. The model simulated $\mathrm{NO}_{3}-\mathrm{N}$ concentrations with an overall Bayesian coefficient of determination of 0.48 . The temporal course of $\mathrm{NO}_{3}-\mathrm{N}$ concentrations was simulated differently well for the individual plots with a maximum plot-specific Nash-Sutcliffe Efficiency of 0.57. The model shows that $\mathrm{NO}_{3}-\mathrm{N}$ concentrations decrease with species richness, but this relation reverses if more than approx. $25 \%$ of legume species are included in the mixture. Presence of legumes increases and presence of grasses decreases $\mathrm{NO}_{3}-\mathrm{N}$ concentrations compared to mixtures containing only small and tall herbs. Altogether, our model shows that there is a strong influence of plant community composition on $\mathrm{NO}_{3}-\mathrm{N}$ concentrations.

Keywords Nitrate in soil solution . Biodiversity · The Jena Experiment · Bayesian model

\section{Introduction}

Evidence accumulates that biodiversity is essential in maintaining the functioning and stability of ecosystems and biogeochemical cycles, but global change 
and human intervention in ecosystems lead to an alarming loss of biodiversity (Hooper et al. 2005; Loreau et al. 2001; Tilman et al. 1997). Disentangling the specific role of plant biodiversity on the $\mathrm{N}$-cycle requires a modeling approach that reflects the complexity of the $\mathrm{N}$-cycle with its multitude of driving factors and players. Process models have been used to derive hypotheses about biodiversity-ecosystem functioning relationships (Loreau 1998). There are several approaches for modeling $\mathrm{NO}_{3}-\mathrm{N}$ concentrations in soil solution, the closest approximation of $\mathrm{N}$ availability for plants, but they don't consider plant diversity, especially not in grasslands. For example, Jonard et al. (2012) used a process-oriented model for nutrient cycling in forests to investigate temporal trends in $\mathrm{NO}_{3}{ }^{-}$and other nutrient concentrations in soil solution. Li et al. (2007) presented a spatially referenced biophysical model for soil water dynamics and $\mathrm{C}$ and $\mathrm{N}$ cycling, which allows the simulation of $\mathrm{NO}_{3}-\mathrm{N}$ concentrations in soil solution on agricultural sites. Other deterministic approaches used for simulating $\mathrm{NO}_{3}-\mathrm{N}$ concentrations in soil solution, mainly aiming at $\mathrm{NO}_{3}-\mathrm{N}$ leaching from cropland, include a processoriented biogeochemical model (Li et al. 2006), a semi-mechanistic agro-ecosystem model (Pedersen et al. 2007), and several other mechanistic models (e.g., Gu and Riley 2010; Riley and Matson 2000; and van der Laan et al. 2010). These models usually require time series of many variables with high temporal resolution and without missing values. Most of the existing deterministic models try to account for the whole $\mathrm{N}$-cycle or even several nutrients. Consequently, these models are extensive, if only $\mathrm{NO}_{3}-\mathrm{N}$ concentrations in soil solution are to be modeled. Statistical models, in contrast, require less parameterization effort and can extract novel information directly from the data and thus provide new insight into ecosystem-processes by giving the opportunity to disentangle processes in the environment that cannot be controlled for in field and laboratory experiments. An important precondition is that statistical models adequately reflect the spatiotemporal heterogeneity of interacting processes.

Unlike classical regression-type models, novel hierarchical Bayesian approaches provide the required level of complexity. Majumdar et al. (2008) and Oleson et al. (2006) successfully developed hierarchical Bayesian models to analyze and predict soil nutrient concentrations as well as Cable et al. (2011) for soil respiration. Bayesian statistical modeling is an emerging method in ecological sciences for quantifying patterns and processes in nature (Clark 2005; Majumdar et al. 2008). In a Bayesian framework, model parameters are considered as random variables and described by a prior distribution from which, in combination with the traditional likelihood, the posterior distribution of the parameter of interest can be obtained (Ntzoufras 2009). For the analysis of a complex Bayesian model, Markov chain Monte Carlo methods (MCMC) are used, which allow simultaneous estimation of large numbers of parameters (Gelman et al. 2003; Ntzoufras 2009), i.e. multiple effects can be modeled simultaneously (Majumdar et al. 2008). The software OpenBUGS (Lunn et al. 2009) allows the development and analysis of complex Bayesian models using MCMC methods. To our knowledge, there is no study that has developed a Bayesian model for $\mathrm{NO}_{3}-\mathrm{N}$ concentrations in soil solution and also no model that is able to simulate the influence of plant diversity on $\mathrm{NO}_{3}-\mathrm{N}$ concentrations in soil solution.

The macronutrient $\mathrm{N}$ is one of the key resources in natural ecosystems (Stevenson and Cole 1999). The processes of the $\mathrm{N}$-cycle are governed by land management (land-use type, fertilizer regime), soil properties (such as $\mathrm{pH}$, soil organic matter concentrations or texture), climatic conditions (air and soil temperature, precipitation, and soil moisture), and deposition from the atmosphere. Plant-available $\mathrm{NO}_{3}$ $\mathrm{N}$ concentrations in soil depend on the relation between uptake by plants and soil organisms, $\mathrm{N}_{2}$ fixation, $\mathrm{N}$ mineralization (i.e. ammonification and nitrification), $\mathrm{N}$ deposition from the atmosphere, denitrification, volatilization and leaching (Corre et al. 2002; Schimel and Bennett 2004). Fertilization of arable land means a nutrient input in the system and often causes increased nitrate leaching, whereas mowing and subsequent removal of the biomass represents a removal of nutrients from the ecosystem. The transition phase after land-use change may take many years, e.g. when fertilized arable land is converted to unfertilized grassland, and the former land-use can still affect ecosystem variables from the new system after several years (Christian and Riche 1998; Oelmann et al. 2007a; Schilling and Spooner 2006). Spatial variations in $\mathrm{NO}_{3}-\mathrm{N}$ concentrations can be caused by differences in soil properties like $\mathrm{pH}$, soil organic matter concentrations, and soil texture controlling soil water content (Corre et al. 2002; Gu and 
Riley 2010). Climatic conditions indirectly drive $\mathrm{NO}_{3}$ $\mathrm{N}$ concentrations in soil because temperature and water availability control plant growth and therefore $\mathrm{N}$ uptake as well as microbial activity (Christian and Riche 1998; Corre et al. 2002). Rosenkranz et al. (2012) found soil water content to be an important driver of net ammonification, which directly influences $\mathrm{NO}_{3}-\mathrm{N}$ concentrations in soil solution. While $\mathrm{N}$ availability is a known driver of species richness (Sala et al. 2000), species richness can in turn also be a driver of $\mathrm{NO}_{3}-\mathrm{N}$ concentrations in soil (Hooper and Vitousek 1998; Niklaus et al. 2001; Oelmann et al. 2007b; Scherer-Lorenzen et al. 2003). Several studies have explored the effects of biodiversity on ecosystem functioning (Hooper and Vitousek 1998; Marquard et al. 2009; Scherer-Lorenzen et al. 2003; Tilman et al. 1996; Tilman et al. 1997). Plant diversity appears to enhance plant productivity and resource use (Hooper et al. 2005; Marquard et al. 2009; Oelmann et al. 2007c; Tilman et al. 1997). In grassland plant diversity experiments, it was found that plant species richness and functional group identity influence $\mathrm{NO}_{3}-\mathrm{N}$ concentrations in soil solution (Hooper and Vitousek 1998; Niklaus et al. 2001; Oelmann et al. 2007a; Scherer-Lorenzen et al. 2003). Complementary and thus more exhaustive resource use of different plant species (Hooper et al. 2005; Hooper and Vitousek 1998; Tilman et al. 1996) was assumed to explain decreasing $\mathrm{NO}_{3}-\mathrm{N}$ concentrations with increasing plant species richness. In addition, plant functional group identity (and partially also functional group richness) influences $\mathrm{NO}_{3}-\mathrm{N}$ concentrations since legumes are known to increase $\mathrm{NO}_{3}-\mathrm{N}$ concentrations because of their symbiotic $\mathrm{N}_{2}$ fixation ability and grasses decrease $\mathrm{NO}_{3}-\mathrm{N}$ concentrations because of their dense and extensive rooting system and a more efficient exploitation of $\mathrm{N}$ resources (Hooper and Vitousek 1998; Oelmann et al. 2007b; Scherer-Lorenzen et al. 2003).

The objectives of our study were (i) to develop a general model capable of simultaneously simulating monthly mean $\mathrm{NO}_{3}-\mathrm{N}$ concentrations in soil solution of all plots of a manipulative biodiversity experiment in grassland (The Jena Experiment) driven by plant species and functional group richness and functional composition and (ii) to investigate the effects of plant species and functional group richness and functional composition on $\mathrm{NO}_{3}-\mathrm{N}$ concentrations in soil solution (0-30 cm depth) taking into account the effects of conversion from arable land to grassland, soil properties, and climate.

\section{Methods}

This study was conducted as part of the Jena Experiment (www.the-jena-experiment.de), which is a grassland plant diversity experiment addressing the role of biodiversity for element cycling and trophic interactions (Roscher et al. 2004).

Study site

The field site is located close to the city of Jena, Germany $\left(50^{\circ} 55^{\prime} \mathrm{N}, 11^{\circ} 35^{\prime} \mathrm{E} ; 130 \mathrm{~m}\right.$ above sea level) on the floodplain of the Saale river. Mean annual air temperature is $9.3^{\circ} \mathrm{C}$ and mean annual precipitation is 587 mm (1961-1990, Kluge and Müller-Westermeier 2000). The soil is an Eutric Fluvisol that developed from up to $2 \mathrm{~m}$ thick loamy fluvial sediments, almost free of stones. As a result of the fluvial dynamics, the texture ranges from sandy loam near the river to silty clay with increasing distance from the river. The site was converted from grassland to an arable field in the 1960s and consequently fertilized and plowed for crop production until the beginning of the grassland plant diversity experiment in 2002.

The entire experimental design is described in Roscher et al. (2004). Briefly, the main experiment comprises 82 plots $(20 \mathrm{~m} \times 20 \mathrm{~m})$ grouped in 4 blocks located in parallel to the river Saale (considering the systematic variation in soil texture). Each of the 82 plots is vegetated by $1,2,4,8,16$, or 60 plant species and 1,2,3, or 4 different plant functional groups (grasses, small herbs, tall herbs, legumes) chosen by the random replacement method from a species pool of 60 species from the Molinio-Arrhenatheretea meadows, Arrhenatherion community (Ellenberg 1996). In this study, we used data from 62 plots from blocks 1-3. As there was a strong correlation between the number of sown species and the realized species richness $\left(R^{2}>0.9\right.$ in each year 2003-2007, Marquard et al. 2009), the successful establishment of the species richness gradient can be assumed, and we will use the term species richness hereafter. The management of all plots was adapted to extensive meadows used for hay production and mown twice a year in June and September. The plots were weeded 
regularly to maintain the sown species composition. During the experimental period, the plots were not fertilized.

\section{Input data}

For the $\mathrm{NO}_{3}-\mathrm{N}$-concentration model, data between January 2003 and December 2006 was used. Data for $\mathrm{NO}_{3}-\mathrm{N}$ concentration in soil solution was available between January 2003 and December 2006 for 62 plots from blocks 1 to 3 . The dataset includes $\mathrm{NO}_{3}-\mathrm{N}$ concentrations reported by Oelmann et al. (2007a, c) for March 2003-May 2004 and additional data not included in the published work of Oelmann et al. (2007a, c). Sampling and measurement of soil solution is described in Oelmann et al. (2007c). Briefly, soil solution was collected with suction plates (UMS, Munich, Germany, sintered glass, diameter $0.12 \mathrm{~m}$, pore size $1-1.6 \mu \mathrm{m}$ ) every second week at $30 \mathrm{~cm}$ depth. $\mathrm{NO}_{3}-\mathrm{N}$ concentration was measured photometrically with a Continuous Flow Analyzer (CFA) after cadmium reduction of nitrate to nitrite and reaction with sulfanilamide and naphthylenediamine-dihydrochloride to an azo-dye. The unknown contribution of nitrite that is contained in the $\mathrm{NO}_{3}-\mathrm{N}$ concentration is expected to be small (Oelmann et al. 2007c). Furthermore, plot-specific data were used from the 62 plots comprising plant species richness $(s r \in\{1$, $2,4,8,16,60\})$, number of functional groups ( $f g \in$ $\{1,2,3,4\})$, absence (0) or presence (1) of legumes (legumes $\in\{0,1\}$ ), grasses (grasses $\in\{0,1\}$ ), small herbs (sherbs $\in\{0,1\}$ ), and tall herbs (therbs $\in\{0,1\}$ ), as well as percentage of legume species (pleg), grass species (pgra), small herb species (psh), and tall herb species ( $p t h)$ out of total species number, and clay (clay) and sand (sand) content of the individual plots. For clay and sand the respective mean content in 0-30 cm depth was calculated from measurements in 10,20 , and $30 \mathrm{~cm}$ depth for each plot in 2002 (Kreutziger 2006). Moreover, monthly meteorological data from the central field station including mean air temperature at $2 \mathrm{~m}$ height in ${ }^{\circ} \mathrm{C}(T)$, monthly precipitation in $\mathrm{mm}(P)$, mean soil moisture in 8,16 , and $32 \mathrm{~cm}$ depth in vol\% $(\mathrm{sm})$, and mean soil temperature in $2,4,8,16$, and $32 \mathrm{~cm}$ depth in ${ }^{\circ} \mathrm{C}(s t)$ was used as input data. To account for the temporal influence since conversion from agriculture to grassland, time in months since January 2002 (time $\in$ $\{13,14, \ldots, 60\}$, i.e. January 2003-December 2006) and year since 2002 (year $\in\{2,3,4,5\}$ ) were also included in the data set.

All calculations were done with the $\mathrm{R}$ 2.11.1 software package (R Development Core Team 2006). To ensure that only positive $\mathrm{NO}_{3}-\mathrm{N}$ concentrations will be simulated by the model and given that the $\mathrm{NO}_{3}-\mathrm{N}$ concentrations are approximately log-normally distributed, we used the logarithm of $\mathrm{NO}_{3}-\mathrm{N}$ concentration in soil solution. To allow the calculation of the logarithm, not detected $\mathrm{NO}_{3}-\mathrm{N}$ concentration values were replaced by $0.01 \mathrm{mg} \mathrm{L}^{-1}$, i.e. half the detection limit for $\mathrm{NO}_{3}-\mathrm{N}$ of the CFA (Oelmann et al. 2007c). $\mathrm{NO}_{3}-\mathrm{N}$ concentration values higher than mean $+2 * S D=$ $21.73 \mathrm{mg} \mathrm{L}^{-1}$ (with mean $=2.42 \mathrm{mg} \mathrm{L}^{-1}$ and standard deviation $S D=9.66 \mathrm{mg} \mathrm{L}^{-1}, n=1,972$ ) were assumed to be outliers and set to not available (NA). Then, monthly mean concentrations were calculated for each plot and finally the $\mathrm{NO}_{3}-\mathrm{N}$ concentrations were log-transformed.

Plant species richness ( $s r$ ) of each plot was transformed to $\log (s r)$ because this transformation represents the expected species richness effect best. Furthermore, the depth-weighted means of soil moisture $(s m)$ and soil temperature $(s t)$ for $0-30 \mathrm{~cm}$ depth were calculated for each month. The variable time was transformed to $\frac{1}{\sqrt{\text { time }}}$ because the effect of time since conversion from an agricultural field to grassland is expected to first rapidly decrease with time and then converge to zero, as for instance the results of Christian and Riche (1998) show.

Summary statistics for all measured input data and the plot specific data are shown in Table 1, illustrating an equal distribution of plant functional groups and species richness in the considered plots of the Jena Experiment. Concerning the $\mathrm{NO}_{3}-\mathrm{N}$ concentrations, a high occurrence of very small values can be observed which supports the decision to work with a $\log$ transformation of these data. $18 \%$ of the very small $\mathrm{NO}_{3}-\mathrm{N}$ concentrations were below the detection limit, and we did not exclude them from the data set because they still contain the information that $\mathrm{NO}_{3}-\mathrm{N}$ concentrations were very low at the corresponding plot and time. An exclusion of these values would cause the model to estimate misleadingly higher $\mathrm{NO}_{3}-\mathrm{N}$ concentrations. The high number of missing $\mathrm{NO}_{3}-\mathrm{N}$ values $(59 \%)$ is a common problem in soil solution sampling. It is mainly caused by very dry conditions in summer and autumn or failure of the sampling system 
Table 1 Summary statistics of input variables

\begin{tabular}{|c|c|c|c|c|c|c|c|c|}
\hline Variable & Min. & $25 \%$ Quantile & Median & Mean & $75 \%$ Quantile & Max. & $n$ & Missing \\
\hline $\mathrm{T}\left({ }^{\circ} \mathrm{C}\right)^{\mathrm{a}}$ & -3.15 & 4.05 & 9.57 & 9.63 & 15.64 & 22.06 & 48 & 0 \\
\hline $\mathrm{P}\left(\mathrm{mm} \mathrm{month}{ }^{-1}\right)^{\mathrm{b}}$ & 6.2 & 23.38 & 37.35 & 40.12 & 47.28 & 127.6 & 48 & 0 \\
\hline $\operatorname{sm}(\operatorname{vol} \%)^{\mathrm{c}}$ & 16.24 & 20.93 & 27.53 & 26.86 & 32.19 & 43.82 & 48 & 0 \\
\hline st $\left({ }^{\circ} \mathrm{C}\right)^{\mathrm{d}}$ & 0.13 & 4.1 & 9.42 & 10.32 & 16.42 & 22.3 & 48 & 0 \\
\hline $\mathrm{NO}_{3}-\mathrm{N}\left(\mathrm{mg} \mathrm{L}^{-1}\right)^{\mathrm{e}}$ & 0.01 & 0.03 & 0.12 & 1.48 & 0.7 & 20.36 & 2,976 & 1,766 \\
\hline $\mathrm{sr}^{\mathrm{f}}$ & 1 & 2 & 4 & 8.65 & 8 & 60 & 62 & 0 \\
\hline $\mathrm{fg}^{\mathrm{g}}$ & 1 & 1 & 2 & 2.11 & 3 & 4 & 62 & 0 \\
\hline legumes ${ }^{\mathrm{h}}$ & 0 & 0 & 1 & 0.53 & 1 & 1 & 62 & 0 \\
\hline grasses $^{\mathrm{h}}$ & 0 & 0 & 1 & 0.56 & 1 & 1 & 62 & 0 \\
\hline sherbs $^{\mathrm{h}}$ & 0 & 0 & 1 & 0.52 & 1 & 1 & 62 & 0 \\
\hline therbs ${ }^{\mathrm{h}}$ & 0 & 0 & 0.5 & 0.5 & 1 & 1 & 62 & 0 \\
\hline pleg $^{\mathrm{i}}$ & 0 & 0 & 0.2 & 0.25 & 0.38 & 1 & 62 & 0 \\
\hline pgra $^{i}$ & 0 & 0 & 0.25 & 0.29 & 0.5 & 1 & 62 & 0 \\
\hline $\mathrm{psh}^{\mathrm{i}}$ & 0 & 0 & 0.2 & 0.23 & 0.36 & 1 & 62 & 0 \\
\hline $\mathrm{pth}^{\mathrm{i}}$ & 0 & 0 & 0.13 & 0.23 & 0.33 & 1 & 62 & 0 \\
\hline Clay content (\%) & 14.64 & 17.43 & 21.44 & 20.78 & 24.10 & 26.03 & 62 & 0 \\
\hline Sand content (\%) & 10.45 & 13.94 & 21.59 & 25.56 & 35.21 & 47.31 & 62 & 0 \\
\hline
\end{tabular}

a Air temperature

b Monthly precipitation

c Soil moisture in 0-30 cm depth

d Soil temperature in 0-30 cm depth

e $\mathrm{NO}_{3}-\mathrm{N}$ concentration in soil solution

${ }^{\mathrm{f}}$ Species richness

g Number of functional groups

h Presence (1) or absence (0) of legumes, grasses, small herbs (sherbs), and tall herbs (therbs), respectively

${ }^{\mathrm{i}}$ Percentage of legumes (pleg), grasses (pgra), small herbs (psh), and tall herbs (pth), respectively, out of total species number

and further justifies the need to develop a model that can estimate these missing values.

Measures for model quality

Several measures were used to determine the model quality. The Deviance Information Criterion (DIC), introduced by Spiegelhalter et al. (2002), was used during model development. The DIC depends on the deviance and the number of "effective" parameters used in a model. A model with smaller DIC can be considered to be better than a model with higher DIC. The Bayesian coefficient of determination $R_{B}^{2}$ (Eq. 1)

$R_{B}^{2}=1-\frac{\sigma_{s i m}^{2}}{\sigma_{d a t}^{2}}$

with the variance of the model $\sigma_{\text {sim }}^{2}$ and the sample variance of the response data $\sigma_{d a t}^{2}$ can be interpreted as the proportional reduction of uncertainty obtained through inclusion of the explanatory variables in the model (Ntzoufras 2009). In posterior predictive model checks data are used twice, first for estimating the posterior predictive density and second for comparing this predictive density with the data (Ntzoufras 2009). Although posterior predictive checks could be considered as too liberal, e.g. Kéry (2010), Meng (1994) and Ntzoufras (2009) argue in favor of using them to assess the discrepancy between model and data. The Bayesian $p$-value (Gelman et al. 1996) quantifies the proportion of times when the lack of fit of a perfect data set (a replicated data set generated using the same model that is fitted to the actual data set) is greater than the lack of fit of the actual data set. A Bayesian $p$-value close to 0.5 indicates that the model fits the data (Kéry 2010). To allow a comparison of the Bayesian model to other models (e.g., process-oriented models), the 
following measures were calculated from the observed versus mean simulated $\mathrm{NO}_{3}-\mathrm{N}$ concentrations (for both options: log transformed, as used for modeling, and back transformed) of all plots and for plots grouped by species number, respectively: mean absolute error (MAE), average error (i.e. mean error, ME), root mean squared error (RMSE) (Janssen and Heuberger 1995) and coefficient of determination $R^{2}$. The quality measures were calculated from the log-transformed $\mathrm{NO}_{3}-\mathrm{N}$ values to show the quality of the model itself and from the back-transformed values to allow comparison with other models. Furthermore, the Nash-Sutcliffe Efficiency (NSE) was calculated to assess the quality of the simulated (log-transformed) time series of the single plots (Nash and Sutcliffe 1970). NSE is a goodness-of-fit measure that ranges from $-\infty$ to 1 , whereas NSE $=1$ indicates a perfect fit.

\section{Model setup procedure}

We assumed a normal distribution (Eq. 2) for the logtransformed $\mathrm{NO}_{3}-\mathrm{N}$ data per time-step $t$ and plot $p\left(\mathrm{NO}_{3}-\mathrm{N}_{t, p}\right)$ with mean $\mu_{t, p}$ and precision $\tau$ (Eq. 3).

$\log \left(N O_{3}-N_{t, p}\right) \sim \operatorname{Normal}\left(\mu_{t, p}, \sigma^{2}=\frac{1}{\tau}\right)$

$\tau \sim G(0.01,0.01)$ with $\mu=1$ and $\sigma^{2}=100$

$\mu_{t, p}$ was defined as a multiple regression (Eq. 4) with parameters $a_{i}$, categorical variables $\left(K_{j}\right)$, and numerical variables and interactions between variables $\left(X_{i}\right)$.

$\mu_{t, p}=\sum\left(a_{i} X_{i}\right)+\sum K_{j}$

A non-informative normal distribution with mean $\mu_{a_{i}}=0$, assuming no effect of $X_{i}$ on $\mathrm{NO}_{3}-\mathrm{N}$ concentrations, and variance $\sigma_{\text {sim }}^{2}=1,000$, representing high uncertainty about the value of $a_{i}$, was assumed for the parameters $a_{i}$ (Eq. 5).

$a_{i} \sim \operatorname{Normal}\left(\mu_{a_{i}}=0, \sigma_{a_{i}}^{2}=\frac{1}{\tau_{a_{i}}}=1,000\right)$

For the categorical variables $\left(K_{j}\right)$ constraints were defined according to Ntzoufras (2009) to make the estimation feasible. A corner constraint was used for the variables indicating the absence or presence of a functional group, i.e. a functional group variable is set to 0 (e.g., legumes $[0]=0)$ if plants of this group are not present on the regarded plot. The absence of a certain functional group hence forms the reference category. The difference caused by the presence of a functional group is estimated by a normally-distributed variable (e.g., legumes[1] $\sim \operatorname{Normal}\left(\mu=0, \sigma^{2}=\right.$ $1,000)$ ).

We accomplished a model selection procedure from various multiple regression models using OpenBUGS (Lunn et al. 2009) which was run from within the R 2.11.1 software package (R Development Core Team 2006) with the packages $R 2$ WinBUGS and BRugs. The final model was run directly in OpenBUGS, because of speed and memory reasons and input data and initial values were written from $\mathrm{R}$ into text files using the function bugs.data.

The variables of the model equation (Eq. 4) were selected using a DIC-based model selection method as described in Ntzoufras (2009, pp. 220-221). At first, variables, which are essential for the modeling purpose and known to have an influence on $\mathrm{NO}_{3}-\mathrm{N}$ in soil solution $\left(\log (s r)\right.$ and $\frac{1}{\sqrt{\text { time }}}$; see "Input data" section for variable definition), were chosen to form an initial model. The next step was to select a set of candidate variables which could potentially improve the initial model. The set of candidate variables consists of categorical variables (absence/presence of legumes, grasses, sherbs, therbs), numerical variables (fg, pleg, pgra, psh, pth, clay, sand, year, $P, T, s m, s t)$ and all interaction terms that can be constructed from two variables out of the numerical variables and the initial variables (all together 107 selectable variables and interaction terms $=$ candidate variables). To decide which candidate variables should be included in the final model, different candidate models were compared according to their DIC. Each candidate model consists of the initial model plus one further variable out of the afore mentioned set of candidate variables. The candidate variable that was included in the best performing candidate model (model with the lowest DIC) was subsequently included in the initial model and removed from the set of candidate variables. Then the procedure was repeated with the new initial model and the reduced set of candidate variables until the difference between the DIC of any candidate model and the DIC of the current initial model was 2 or less. If two or more candidate models resulted in the same, lowest DIC, the variable to be included in the initial model of the next selection run 
was chosen based on expert knowledge. During model development, the DIC decreased from 5317 to 4708 with progressive improvement of the model quality.

Convergence of the final selected model was checked with the modified Gelman-Rubin statistic, as implemented in OpenBUGS. To be conservative, 60,000 iterations were used as "burn-in" and three chains with different random starting values were compared. One of the chains was run for further 120,000 iterations, on which the estimates of the parameters and all further simulations are based.

\section{Model simulations}

Our model interpretation is based on various simulations calculated in OpenBUGS to investigate the effects of selected variables on $\mathrm{NO}_{3}-\mathrm{N}$ concentrations in soil solution and to allow interpretation of all the terms that were selected in the model selection procedure (Table 2). For each simulation, again, the mean of 120,000 iterations was used. To be able to simulate the influence of a certain variable or interaction, the values of the considered variables were deliberately, artificially changed in the model equation while all other variables were kept constant, creating hypothetical conditions which cannot be realized in reality or only with great effort or during (more than feasible) extended experimentation time. This approach allows us to disentangle processes in the environment that cannot be disentangled in field and laboratory experiments or with deterministic models. That is, opposing but inseparable effects can be disentangled with this approach.

We simulated the influence of selected variables by artificially changing their values (within a natural range) in the model equation while the remaining variables were kept constant as follows: For the climate variables $(P, T, s m, s t)$ and clay content (clay), we used the mean values of the input data, rounded to the closest integer (Table 1). Species richness $(\log (s r))$ was set to $\log (16)$ species and number of functional groups $(f g)$ was set to 4 . Furthermore, an equal share of plants from each functional group was set $($ pleg $=$ pgra $=p s h=p t h$ $=0.25$ ) and, hence, the categorical variables grasses and legumes were set as present. The variable $\frac{1}{\sqrt{\text { time }}}$ was set to $\frac{1}{\sqrt{40}}$ (i.e. 40 months since January 2002) and, hence, the variable year to 4 (i.e. year 2005).
Table 2 Estimated values for model parameters

\begin{tabular}{|c|c|c|c|c|}
\hline Parameter $^{\mathrm{a}}$ & Term $^{\text {b }}$ & Mean & $\begin{array}{l}2.5 \% \\
\text { Quantile }\end{array}$ & $\begin{array}{l}97.5 \% \\
\text { Quantile }\end{array}$ \\
\hline $\mathrm{a}_{1}$ & $\log \left(s r_{p}\right)$ & -0.599 & -0.809 & -0.387 \\
\hline$a_{2}$ & $\frac{1}{\sqrt{\text { time }_{t}}}$ & 26.830 & 15.980 & 36.310 \\
\hline $\mathrm{a}_{3}$ & $\operatorname{pleg}_{p} \cdot \frac{1}{\sqrt{\text { time }_{t}}}$ & -5.831 & -15.070 & 2.918 \\
\hline $\mathrm{a}_{4}$ & $\operatorname{clay}_{p}$ & -0.554 & -0.669 & -0.444 \\
\hline$a_{5}$ & $\mathrm{P}_{t} \cdot \frac{1}{\sqrt{\text { time }_{t}}}$ & -0.096 & -0.322 & 0.102 \\
\hline$a_{6}$ & $\mathrm{P}_{t} \cdot$ year $_{t}$ & 0.015 & 0.008 & 0.021 \\
\hline$a_{7}$ & $\operatorname{clay}_{p} \cdot \frac{1}{\sqrt{\text { time }_{t}}}$ & 2.161 & 1.653 & 2.711 \\
\hline$a_{8}$ & $\operatorname{pleg}_{p} \cdot$ year $_{t}$ & 0.082 & -0.234 & 0.399 \\
\hline$a_{9}$ & $\operatorname{psh}_{p} \cdot \operatorname{pleg}_{p}$ & -9.600 & -12.660 & -6.532 \\
\hline$a_{10}$ & $\operatorname{pth}_{p} \cdot \operatorname{pgra}_{p}$ & -1.288 & -3.128 & 0.547 \\
\hline $\mathrm{a}_{11}$ & $\operatorname{pleg}_{p} \cdot \log \left(s r_{p}\right)$ & 0.867 & 0.458 & 1.277 \\
\hline$a_{12}$ & $\mathrm{~T}_{t} \cdot$ year $_{t}$ & -0.022 & -0.033 & -0.012 \\
\hline$a_{13}$ & $\mathrm{sm}_{t} \cdot \mathrm{P}_{t}$ & -0.001 & -0.003 & 0.001 \\
\hline$a_{14}$ & $\mathrm{pth}_{p} \cdot \operatorname{pleg}_{p}$ & -8.143 & -11.680 & -4.615 \\
\hline$a_{15}$ & $\mathrm{fg}_{p} \cdot \log \left(s r_{p}\right)$ & 0.091 & 0.007 & 0.174 \\
\hline$a_{16}$ & $\operatorname{pgra}_{p} \cdot$ year $_{t}$ & 0.299 & 0.131 & 0.467 \\
\hline$a_{17}$ & $\operatorname{year}_{t} \cdot \frac{1}{\sqrt{\text { time }_{t}}}$ & -18.680 & -22.920 & -13.940 \\
\hline $\mathrm{a}_{18}$ & year $_{t}$ & 2.086 & 1.478 & 2.682 \\
\hline$a_{19}$ & $\operatorname{clay}_{p} \cdot \operatorname{year}_{t}$ & 0.026 & 0.006 & 0.045 \\
\hline$a_{20}$ & $\operatorname{pleg}_{p} \cdot \mathrm{T}_{t}$ & -0.051 & -0.101 & -0.001 \\
\hline $\mathrm{a}_{21}$ & $\mathrm{P}_{t} \cdot \mathrm{T}_{t}$ & -0.001 & -0.002 & 0.000 \\
\hline$a_{22}$ & $\mathrm{~T}_{t} \cdot \mathrm{st}_{t}$ & 0.005 & 0.001 & 0.009 \\
\hline$a_{23}$ & $\operatorname{clay}_{p} \cdot \operatorname{pleg}_{p}$ & 0.105 & 0.010 & 0.202 \\
\hline gra & grasses $_{p}$ & -1.401 & -1.942 & -0.861 \\
\hline leg & legumes $_{p}$ & 1.140 & 0.085 & 2.203 \\
\hline sd.N & $\begin{array}{l}\text { Standard } \\
\text { deviation }\end{array}$ & 1.675 & 1.608 & 1.743 \\
\hline
\end{tabular}

a see "Model setup procedure" section for parameter definition

b see "Input data" section for variable explanation

\section{Results and discussion}

Model for $\mathrm{NO}_{3}-\mathrm{N}$ concentration in soil solution

\section{Selected model}

The final, most parsimonious general model for $\mathrm{NO}_{3}$ $\mathrm{N}$ concentrations in soil solution in $0-30 \mathrm{~cm}$ depth of all 62 plots resulted in Eqs. 2-5 with the following explanatory variables selected from the numerical variables and interactions between variables $\left(X_{i}\right)$ and 
categorical variables $\left(K_{j}\right)$ by the model selection procedure (see also Table 2 ).

$$
\begin{aligned}
& X_{i} \in\left\{\log \left(\text { sr }_{p}\right), \frac{1}{\sqrt{\text { time }_{t}}}, \text { pleg }_{p} \cdot \frac{1}{\sqrt{\text { time }_{t}}}, \text { clay }_{p},\right. \\
& P_{t} \cdot \frac{1}{\sqrt{\text { time }_{t}}}, P_{t} \cdot \text { year }_{t}, \text { clay }_{p} \cdot \frac{1}{\sqrt{\text { time }_{t}}}, \text { pleg }_{p} \cdot \text { year }_{t}, \\
& \text { psh }_{p} \cdot \text { pleg }_{p}, \text { pth }_{p} \cdot \text { pgra }_{p}, \text { pleg }_{p} \cdot \log \left(\text { sr }_{p}\right), \\
& T_{t} \cdot \text { year }_{t}, \text { sm }_{t} \cdot P_{t}, \text { pth }_{p} \cdot \text { pleg }_{p}, f_{p} \cdot \log \left(\text { sr }_{p}\right), \\
& \text { pgra }_{p} \cdot \text { year }_{t}, \frac{1}{\sqrt{\text { time }_{t}}} \cdot \text { year }_{t}, \text { year }_{t}, \text { clay }_{p} \cdot \text { year }_{t}, \\
& \text { pleg } \left._{p} \cdot T_{t}, P_{t} \cdot T_{t}, T_{t} \cdot \text { st }_{t}, \text { clay }_{p} \cdot \text { pleg }_{p}\right\} \\
& K_{j} \in\left\{\text { legumes }_{p}, \text { grasses }_{p}\right\}
\end{aligned}
$$

The model uses 15 variables that are included as individual variables or in an interaction term. Both time variables, months since January 2002 (time) and year since 2002 (year) are included in the model as well as clay content (clay). Furthermore, the climate variables soil moisture $(\mathrm{sm})$, soil temperature $(s t)$, precipitation $(P)$, and air temperature $(T)$ were selected during the selection procedure. The included plant diversity variables comprise species richness $(s r)$, functional group richness $(f g)$, percentage of legumes (pleg), percentage of grasses (pgra), percentage of small herbs ( $p s h)$, percentage of tall herbs ( $p t h)$, and the categorical variables indicating the presence/ absence of legumes (legumes) and grasses (grasses), respectively. The variables sand content, presence of small herbs, and presence of tall herbs are not included in the final model.

Convergence of the final $\mathrm{NO}_{3}-\mathrm{N}$ model occurred within 15,000 updates. The estimates of the model equation parameters $\left(a_{i}\right)$ are presented in Table 2.

\section{Model quality}

The Bayesian coefficient of determination resulted in mean $\mathrm{R}_{B}^{2}=0.48(\mathrm{SD}=0.02,2.5 \%$ quantile $=0.43$, $97.5 \%$ quantile $=0.52$ ). The model has a Bayesian $p$ value of 0.50 , which indicates that the model fits the observed data. A $p$ value approaching 0 or 1 would have indicated irrelevance of the model. In Fig. 1, all observed $\mathrm{NO}_{3}-\mathrm{N}$ concentrations in soil solution are plotted against the simulated concentrations. The lack of accuracy of the measured $\mathrm{NO}_{3}-\mathrm{N}$ concentrations below the detection limit (see "Input data" section) causes the piled points on the left of the detection limit

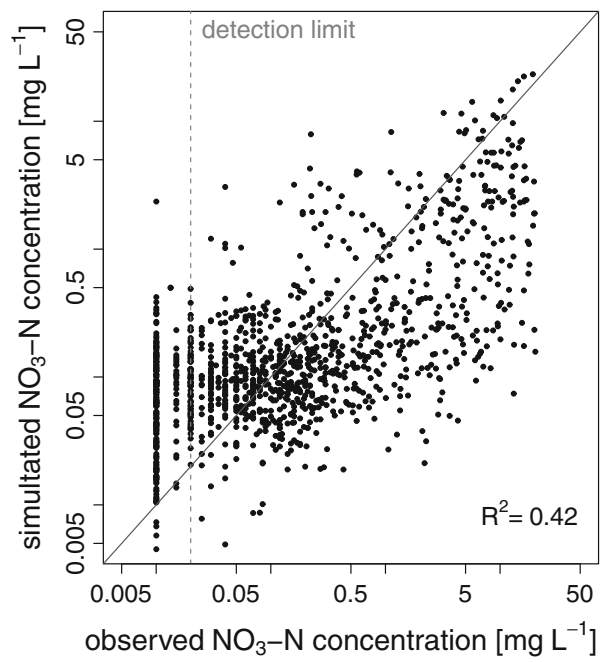

Fig. 1 Simulated and measured $\mathrm{NO}_{3}-\mathrm{N}$ concentrations in soil solution $\left(\mathrm{mg} \mathrm{L}^{-1}\right)$ and 1:1 line

line. However, the piled points also show that the model overestimates very low $\mathrm{NO}_{3}-\mathrm{N}$ concentrations. The posterior predictive quality measures of all simulated versus all observed $\mathrm{NO}_{3}-\mathrm{N}$ concentrations are summarized in Table 3 . The inaccuracy in measured $\mathrm{NO}_{3}-\mathrm{N}$ concentrations below the detection limit probably narrowed model quality, but an exclusion of these values would have caused a more severe misdirection of the model, resulting in a general overestimation of low values.

The calculated quality or predictability measures for observed versus simulated $\mathrm{NO}_{3}-\mathrm{N}$ concentration grouped by species richness show an increase in predictability with species richness (Table 3). This is probably not caused by increasing ecosystem stability with increasing species richness because we did not find a significant correlation between the coefficient of variation for $\mathrm{NO}_{3}-\mathrm{N}$ concentrations and species richness. Proulx et al. (2010) found no species richness effect on variation in belowground ecological functions as well as on soil nutrient concentrations. The decrease in predictability with decreasing species richness might possibly originate from a stronger variation in climate data like air and soil temperature in less diverse plant mixtures than in more diverse mixtures. This difference in variation could be caused by microclimatic differences, e.g. because of an increase in shading in more diverse mixtures which have more biomass and a higher plant cover (Marquard et al. 2009; Spehn et al. 2000). As only climate 
Table 3 Posterior predictive model quality measures: ME, MAE, RMSE, and $\mathrm{R}^{2}$ for simulated versus observed $\mathrm{NO}_{3}-\mathrm{N}$ values (for both log-transformed values, as used for modeling, and back-transformed values) for all values and for values aggregated by species richness $(s r)$

\begin{tabular}{|c|c|c|c|c|c|c|c|c|}
\hline \multirow[t]{2}{*}{ sr (-) } & \multicolumn{4}{|c|}{ Log-transformed $\mathrm{NO}_{3}-\mathrm{N}$} & \multicolumn{4}{|c|}{ Back-transformed $\mathrm{NO}_{3}-\mathrm{N}$} \\
\hline & $\mathrm{ME}(-)$ & MAE (-) & RMSE (-) & $\mathrm{R}^{2}(-)$ & $\mathrm{ME}\left(\mathrm{mg} \mathrm{L}^{-1}\right)$ & $\operatorname{MAE}\left(\mathrm{mg} \mathrm{L}^{-1}\right)$ & $\operatorname{RMSE}\left(\mathrm{mg} \mathrm{L}^{-1}\right)$ & $\mathrm{R}^{2}(-)$ \\
\hline All & -0.00031 & 1.33 & 1.66 & 0.42 & -0.85 & 1.18 & 3.05 & 0.27 \\
\hline 1 & -0.31 & 1.61 & 1.98 & 0.31 & -2.16 & 2.72 & 5.10 & 0.16 \\
\hline 2 & 0.32 & 1.42 & 1.75 & 0.36 & -0.59 & 1.18 & 2.92 & 0.25 \\
\hline 4 & 0.05 & 1.24 & 1.55 & 0.45 & -0.61 & 0.88 & 2.41 & 0.41 \\
\hline 8 & 0.19 & 1.18 & 1.46 & 0.48 & -0.43 & 0.67 & 1.97 & 0.45 \\
\hline 16 & -0.22 & 1.24 & 1.52 & 0.29 & -0.42 & 0.48 & 1.61 & 0.54 \\
\hline 60 & -0.13 & 1.13 & 1.39 & 0.44 & -0.58 & 0.64 & 2.06 & 0.54 \\
\hline
\end{tabular}

data from the central meteorological station and no plot-specific measurements were available, we can only speculate that the used climate variables were less representative and had less explanatory power for low diverse mixtures. Another possible explanation for increasing predictability with species richness might be the generalizing structure of the model for differently diverse plant mixtures. In low diverse mixtures, several explanatory variables in the model equation have the value 0 . For example, in the case of a grass monoculture, the variables legumes, pleg, psh, and $p t h$ have the value 0 . This reduces the number of terms explaining $\mathrm{NO}_{3}-\mathrm{N}$ concentrations in low diverse mixtures and therefore the flexibility of the multiple regression equation. 62 separate models, for each plot a different model, would have probably resulted in better predictability. However, the generalizing view on the 62 plots with different plant diversity has the big advantage that it allows to extract new information from the whole data set, but with the drawback that model quality might have become weaker for less diverse mixtures.

The simulated and observed $\mathrm{NO}_{3}-\mathrm{N}$ concentrations in soil solution (log-transformed) were plotted for the three plots with the best and the three plots with the worst NSE (Fig. 2). The maximum plot-specific NSE is 0.57 and was reached on a 8 and a 4 -species plot. The lowest NSE was found on a 2 -species plot. We also found a correlation between number of missing values per plot and NSE $(\mathrm{R}=-0.27)$. This is reasonable because there was less information available from plots with many missing values and therefore these plots had less influence on model development. For most plots, the range of the observed values is met reasonably well by the model. When looking at the plots with a bad NSE, we found that 4 out of the 9 worst simulated plots have 2 species, 1 functional group and no tall herbs in common (including plots B2A02 and B3A21, Fig. 2). For some of these 2-species plots $\mathrm{NO}_{3}-\mathrm{N}$ concentrations are overestimated (e.g., B2A02) and for some underestimated (e.g., B3A21). This leads to the conclusion that there are high variations between plots with these properties and therefore $\mathrm{NO}_{3}-\mathrm{N}$ concentrations could not be simulated better using the given set of explanatory variables. Further analyses showed that the insufficient simulation of $\mathrm{NO}_{3}-\mathrm{N}$ concentrations in soil solution of plot B3A05 (Fig. 2) is probably attributable to the fact that this 8 -species plot had the highest measured biomass of all plots in August 2003 and May 2006, qualifying it as an outlier (Weigelt et al. 2010).

Besides the independent development of individual models for each of the 62 plots, which would, however, not have allowed for the in-depth evaluation using the experimental design, the quality of the general model for all 62 plots could have possibly been improved by including further known controls of $\mathrm{NO}_{3}$ $\mathrm{N}$ concentrations in soil solution. These controls include microclimatic conditions (e.g., soil temperature per plot) which affect microbial transformation processes, measures of microbial activity (e.g., microbial biomass or respiration), redox potential, or soil carbon to $\mathrm{N}$ ratios. Moreover, $\mathrm{N}$ concentrations in throughfall, which significantly differed between plots with and without legumes (Oelmann et al. 2007a), could have improved the model. But these controls were either not measured, only measured on a 


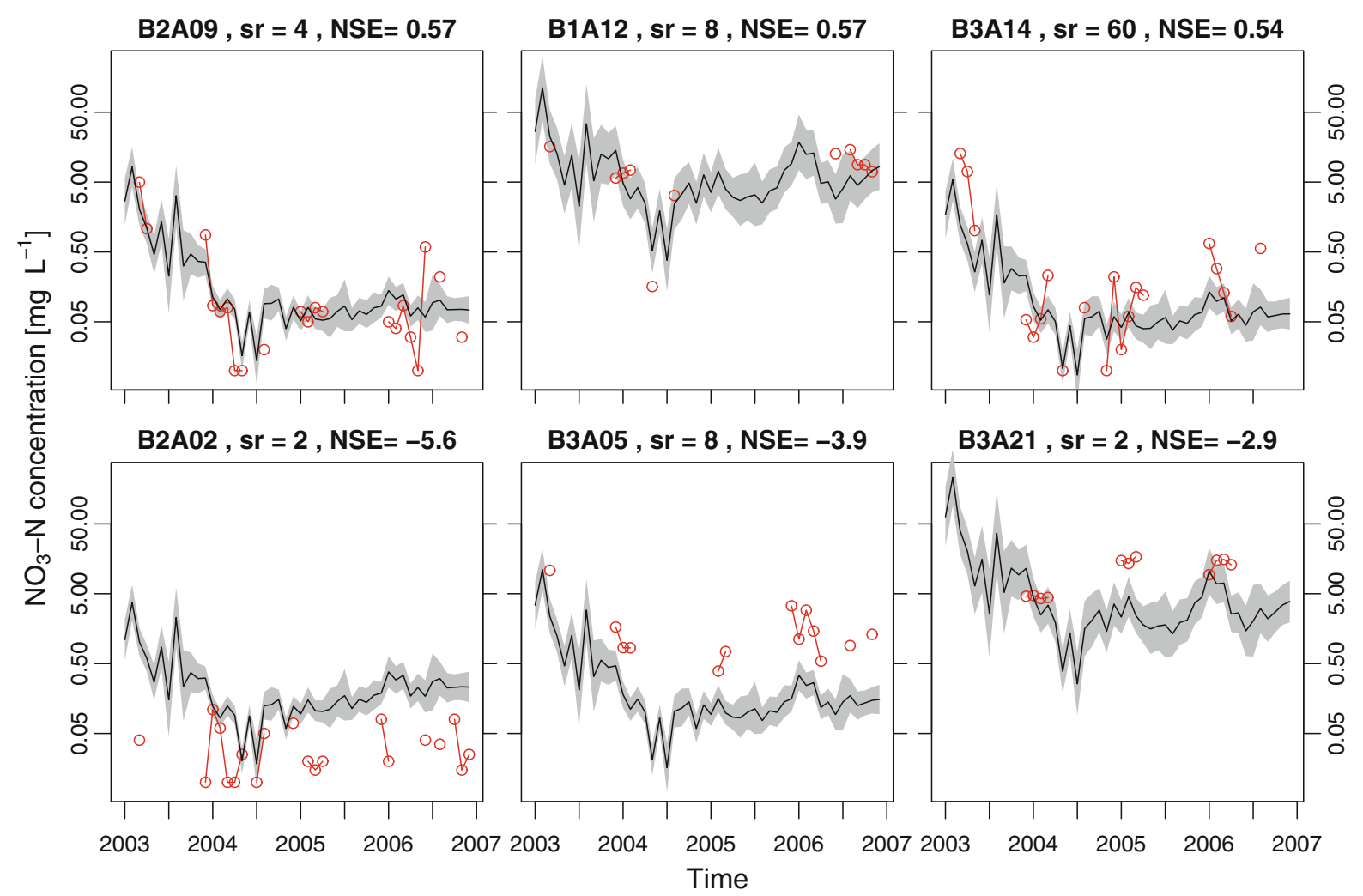

Fig. 2 The three plots with the best NSE and the three plots with the worst NSE. Simulated mean $\mathrm{NO}_{3}-\mathrm{N}$ concentrations in soil solution $\left(\mathrm{mg} \mathrm{L}^{-1}\right)$ (solid continuous line) and $95 \%$ credible

relatively small subset of the 62 plots, or measured in a very coarse temporal resolution which could not have been included in the model. Macroclimatic conditions, land use, topography, and $\mathrm{pH}$ are further controls of $\mathrm{NO}_{3}-\mathrm{N}$ concentrations in soil solution used in other models to explain variation in $\mathrm{NO}_{3}-\mathrm{N}$ concentrations in soil solution. Because of the relatively small size of our study site, these controls show no (e.g., macroclimate) or only a limited variation [in 2002, $\mathrm{pH}$ was between 7.1 and 8.4 , i.e. all within carbonate buffer (Oelmann et al. 2007b)]. The limited variation results in a limited explanatory capability of these controls for $\mathrm{NO}_{3}-\mathrm{N}$ concentration in soil solution at our study site and therefore the model would not be improved by inclusion of these variables. Modeling $\mathrm{NO}_{3}-\mathrm{N}$ concentrations on a finer temporal scale might improve model quality, but handling of such a big dataset (already almost 3,000 $\mathrm{NO}_{3}-\mathrm{N}$ concentrations in monthly resolution whereas each concentration is estimated from 120,000 iterations) would probably not interval (shaded area) per month (years 2003-2006) as well as measured $\mathrm{NO}_{3}-\mathrm{N}$ concentrations (connected circles)

be possible because of computational memory limitations. The incorporation of a random plot effect like in Kristensen et al. (2004), resulting in a linear mixed model, would probably increase model quality but at the same time make predictions (e.g., for plots of block 4) impossible. Kristensen et al. (2004) investigated $\mathrm{NO}_{3}-\mathrm{N}$ concentration in soil solution in forest ecosystems with mixed linear models and could increase the explanatory power of their model by $34 \%$ through inclusion of such a random site effect. This random site effect explains differences between sites without the identification of a cause. In our study, we accepted a lower $\mathrm{R}^{2}$ through not including a random plot effect because we wanted to extract as much information from known explanatory variables as possible.

Comparing our model to other models which are able to simulate $\mathrm{NO}_{3}-\mathrm{N}$ concentrations in soil solution is difficult, because many studies only report $\mathrm{NO}_{3}-\mathrm{N}$ leaching as final product or give only a graphical comparison between observed and simulated $\mathrm{NO}_{3}-\mathrm{N}$ 
concentrations in soil solution. For instance, $\mathrm{Li}$ et al. (2007) show plots of measured versus simulated $\mathrm{NO}_{3}$ $\mathrm{N}$ concentration in soil solution for two study sites, produced by the spatially referenced biophysical model WNMM. For one study site, the simulated agree well with the measured $\mathrm{NO}_{3}-\mathrm{N}$ concentrations, but for the other site they assume that the discrepancies between observed and simulated values might be caused by strong spatial variation. In our model, clay content per plot is already included to catch spatial variations within the field site, but there might be other spatially varying properties that affect $\mathrm{NO}_{3}-\mathrm{N}$ concentrations in soil solution and are not caught by soil texture. A detailed graphical evaluation of $\mathrm{NO}_{3}{ }^{-}$ concentrations in soil solution in several depths is given by van der Laan et al. (2010). Comparing their figures to Fig. 2, we come to the conclusion that our model shows a similar capability of predicting $\mathrm{NO}_{3}-\mathrm{N}$ concentrations. Pedersen et al. (2007) tested three different variations of the model Daisy and reached a minimum RMSE of $4.0 \mathrm{mg} \mathrm{L}^{-1} \mathrm{NO}_{3}-\mathrm{N}$ concentration in soil solution. Except for the monocultures, RMSE of back-transformed simulated $\mathrm{NO}_{3}-\mathrm{N}$ concentrations of our model was below this value (Table 3). With a process-oriented model, Jonard et al. (2012) reached good results for some simulated nutrient concentrations, but for $\mathrm{NO}_{3}{ }^{-}$in soil solution the modeling efficiency (equals NSE) was -0.9. As already pointed out above, our model did not work well on all plots, but 54 of 62 plots had a NSE $>-0.9$. Compared to other models for $\mathrm{NO}_{3}-\mathrm{N}$ concentration in soil solution, as far as a comparison was possible, we judge our model as working satisfyingly well. Majumdar et al. (2008) achieved very high correlations between simulated and observed soil nutrient and carbon pools with a static hierarchical Bayesian model. Predicting the temporal variation in nutrient concentrations correctly is another difficulty that our model had to cope with. A not ideal simulation of these temporal variations possibly resulted in reduced quality measures. Oleson et al. (2006) analyzed $\mathrm{NO}_{3}-\mathrm{N}$ concentrations with a Bayesian approach and found that it yielded similar results as other statistical methods. At the same time, the Bayesian approach resulted in a more accurate description of the explanatory variables, which is one of our objectives addressed in the following sections. Another Bayesian approach in the field of biogeochemistry was successfully applied by Cable et al. (2011) on soil respiration in deserts. Cable et al.
(2011) investigated 7 deserts and achieved model qualities for the different desserts ranging from $\mathrm{R}^{2}=0.33$ to $\mathrm{R}^{2}=0.70$.

\section{Model interpretation}

In the following paragraphs, we present and discuss the results obtained from simulations where the values of selected variables were artificially changed while the remaining variables were kept constant (see "Model simulations" section). Before addressing plant diversity effects on $\mathrm{NO}_{3}-\mathrm{N}$ concentrations in soil solution, we first assessed the possibly interfering effects of time since conversion from arable land to grassland, spatial variations, and climate.

\section{Temporal and spatial effects}

If only the variables $\frac{1}{\sqrt{\text { time }}}$ and year are artificially changed, temporal effects on $\mathrm{NO}_{3}-\mathrm{N}$ concentrations in soil solution caused by the conversion from agriculture to grassland can be observed (Fig. 3). As $\frac{1}{\sqrt{\text { time }}}$ converges to zero with increasing time, positive values for parameters $a$ (Table 2) in combination with the variable $\frac{1}{\sqrt{\text { time }}}$ represent a decrease in $\mathrm{NO}_{3}-\mathrm{N}$ concentrations over time and negative values an increase over time. First, there is a rapid decrease of $\mathrm{NO}_{3}-\mathrm{N}$ concentrations in soil solution after conversion (Fig. 3). This observation complies with the expected development because the area was not fertilized anymore after conversion and $\mathrm{NO}_{3}-\mathrm{N}$ uptake by plants as well as leaching reduced the plant-available $\mathrm{N}$ concentrations in the system. After approximately 4 years, $\mathrm{NO}_{3}-\mathrm{N}$ concentrations started to slowly increase. This coincides with an increase in carbon stocks in the "new" grassland ecosystem (Steinbeiss et al. 2008) and increasing organic matter concentrations result in enhanced ammonium release (Rosenkranz et al. 2012) supplying additional substrate for nitrification.

Although the study area is quite small, spatial variations in clay content had an effect on $\mathrm{NO}_{3}-\mathrm{N}$ concentrations in soil solution (artificially changed variables: clay, $\frac{1}{\sqrt{\text { time }}}$, and year). At the beginning of the second year, $\mathrm{NO}_{3}-\mathrm{N}$ concentrations increased with clay content (Fig. 4). This could be explained by a higher organic matter content on plots with higher clay 


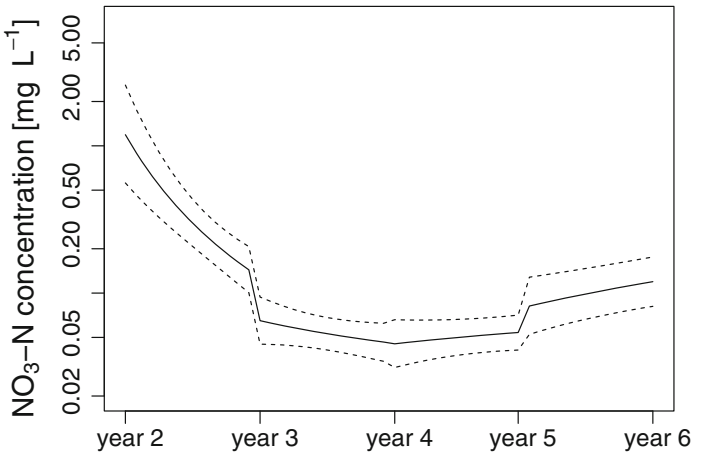

Time since conversion from agriculture to grassland

Fig. $3 \mathrm{NO}_{3}-\mathrm{N}$ concentrations in soil solution over time (solid line) and $95 \%$ credible interval (dashed line) with constant values as described at the beginning of "Model simulations" section

content (correlation between organic carbon concentration and clay content was $\mathrm{R}=0.23$, Steinbeiss et al. 2008) shortly after conversion from the organic matter-depleted agricultural field, which would support a higher mineralization rate and therefore a higher $\mathrm{NO}_{3}-\mathrm{N}$ concentration on plots with higher clay content. But already within the second year, the relation changed and $\mathrm{NO}_{3}-\mathrm{N}$ concentrations increased with decreasing clay content and there was less variation in $\mathrm{NO}_{3}-\mathrm{N}$ concentrations with clay contents. The reason might be that a higher clay content indicates a higher fertility of the soil which improves the growth conditions of plants and further enhances $\mathrm{NO}_{3}-\mathrm{N}$ uptake by plants. The consequences are lower $\mathrm{NO}_{3}-\mathrm{N}$ concentrations with higher clay content.

\section{Climatic effects}

All possible climatic variables were selected in at least one interaction term during the model selection procedure. Some of these interaction terms show a changing influence of the climatic variable over time. Other interaction terms depict the seasonal influences on $\mathrm{NO}_{3}-\mathrm{N}$ concentrations in soil solution.

Over time, the influence of precipitation on $\mathrm{NO}_{3}-\mathrm{N}$ concentrations changed (Fig. 5) if soil moisture and other variables were kept constant according to "Model simulations" section (except $P, \frac{1}{\sqrt{\text { time }}}$, and year which were artificially changed). The parameter associated to the interaction between precipitation and $\frac{1}{\sqrt{\text { time }}}\left(a_{5}\right)$ is not significantly different from zero, but the parameter for precipitation and year $\left(a_{6}\right)$ is (Table 2). In the second year after conversion from agriculture to grassland, $\mathrm{NO}_{3}-\mathrm{N}$ concentrations decreased with increasing monthly precipitation. This is probably attributable to dilution effects as $\mathrm{NO}_{3}-\mathrm{N}$ concentrations were high at the beginning of the experiment (Fig. 3). In the following years a decreasing variation in $\mathrm{NO}_{3}-\mathrm{N}$ concentrations for different precipitation volumes can be observed which could be attributed to the establishment of the system. The establishment of a closed plant cover on the whole experimental field might have reduced small-scale variations within the plots. Moreover, the disappearance of the effects of former fertilization probably reduced variation in $\mathrm{NO}_{3}-\mathrm{N}$ concentrations with precipitation volumes. In the fifth year the variation slightly increased again and, now, $\mathrm{NO}_{3}-\mathrm{N}$ concentrations increased with monthly precipitation. Rosenkranz et al. (2012) found that in-situ net ammonification increased under higher soil moisture which could explain this precipitation effect, if nitrification is assumed to increase as well. On the other hand, if precipitation is kept constant (see "Model simulations" section) and soil moisture is artificially changed, the model simulates generally higher $\mathrm{NO}_{3}-\mathrm{N}$ concentrations at lower soil moisture (Fig. 6). These higher

Fig. $4 \mathrm{NO}_{3}-\mathrm{N}$

concentrations in soil solution for several clay contents over time with constant values as described at the beginning of "Model simulations" section

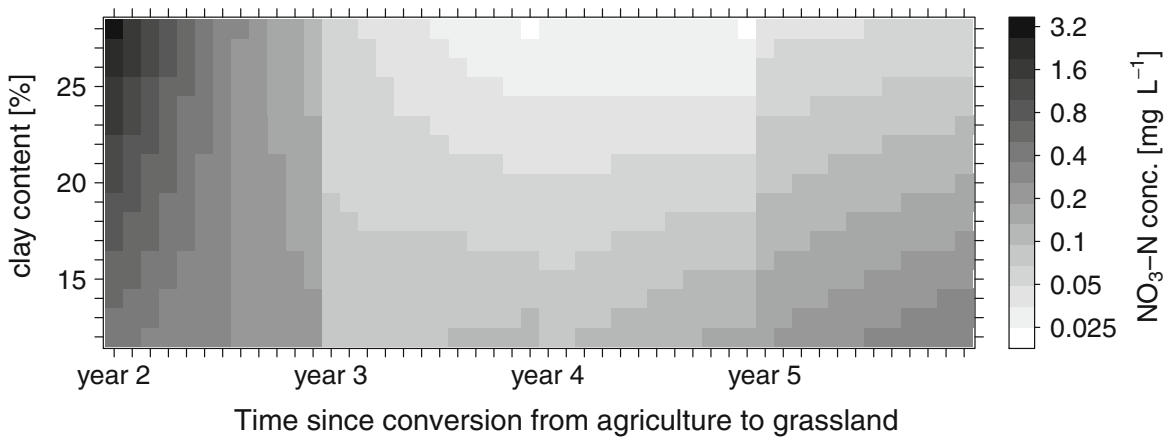


Fig. $5 \quad \mathrm{NO}_{3}-\mathrm{N}$

concentrations in soil solution for varying monthly precipitation over time with constant values as described at the beginning of "Model simulations" section

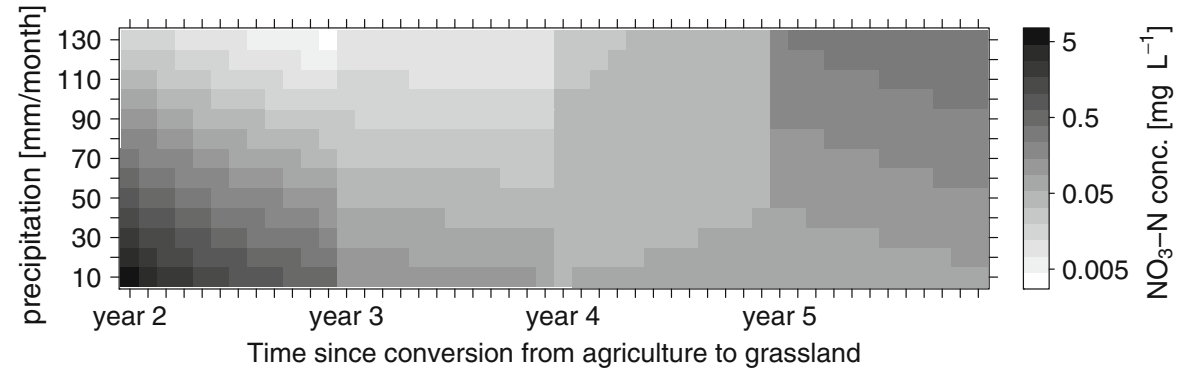

$\mathrm{NO}_{3}-\mathrm{N}$ concentrations under drier conditions could be described as a physical concentration effect. However, the parameter $a_{13}$ of the interaction between precipitation and soil moisture (the only appearance of the variable soil moisture in the model) is not significantly different from zero.

The interaction between air temperature and time (Table 2) continuously showed lower $\mathrm{NO}_{3}-\mathrm{N}$ concentrations at higher temperatures which complies with the vegetation period when plant uptake of $\mathrm{NO}_{3}-\mathrm{N}$ is highest. This implies that air temperature mainly generated the seasonal variation of $\mathrm{NO}_{3}-\mathrm{N}$ concentrations in the model. On the contrary, the interaction between air and soil temperature (Table 2) indicates that $\mathrm{NO}_{3}-\mathrm{N}$ concentrations increase with air and soil temperature. This might be due to increasing evapotranspiration with increasing soil temperature and therefore decreasing soil moisture which leads to the afore mentioned concentration effect under dry soil conditions (i.e. higher $\mathrm{NO}_{3}-\mathrm{N}$ concentrations).

The influence of precipitation on simulated $\mathrm{NO}_{3}-\mathrm{N}$ concentrations differed with air temperature (Fig. 7) if only $P$ and $T$ were varied artificially. At high air temperatures (i.e. in the vegetation period), high precipitation decreased $\mathrm{NO}_{3}-\mathrm{N}$ concentrations. But at low air temperatures (i.e. in winter) $\mathrm{NO}_{3}-\mathrm{N}$ concentrations increased with precipitation. In the vegetation period, this might be a dilution effect of high precipitation causing a decrease in $\mathrm{NO}_{3}-\mathrm{N}$ concentrations. In winter, plant uptake is strongly reduced and as mineralization of $\mathrm{N}$ also occurs at low temperatures, provided that the soil is moist enough (van Schöll et al. 1997), this might explain why $\mathrm{NO}_{3}-\mathrm{N}$ concentrations increase with precipitation in winter. Particularly during frost periods in winter, additional $\mathrm{N}$ might be released from decomposing roots, nodules, and aboveground plant residues and appear in the soil solution especially in months with high precipitation in winter (Dubach and Russelle 1994; Oelmann et al. 2007c).

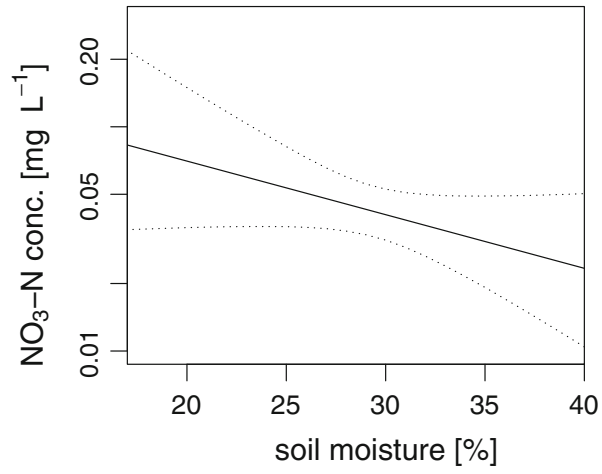

Fig. 6 Influence of soil moisture ( $\mathrm{sm}$ ) on $\mathrm{NO}_{3}-\mathrm{N}$ concentrations in soil solution (solid line) and $95 \%$ credible interval (dotted line). Constant values are as described at the beginning of "Model simulations" section

\section{Effects of species richness and functional group identity}

$\mathrm{NO}_{3}-\mathrm{N}$ concentrations in soil solution decreased with increasing plant species richness in mixtures without legumes (Fig. 8) if species richness and percentage of legumes were artificially changed (and subsequently also legumes, indicating presence or absence of legumes). However, this effect reversed if more than approximately $25 \%$ of a mixture's species number were legumes. This suggests that the fertilizer effect of legumes exceeds the diversity effect. High contributions of legumes in mixtures lead to increased $\mathrm{N}$ availability in soil and thus minimize resource competition associated with no need for complementary $\mathrm{N}$ uptake. This threshold value can also be interpreted as the transformation of a complementarity effect at a low species contribution of legumes to a functional group identity effect at a high species contribution of legumes. The interaction term between species richness and functional group number shows an increase in $\mathrm{NO}_{3}-\mathrm{N}$ concentrations with increasing species and 


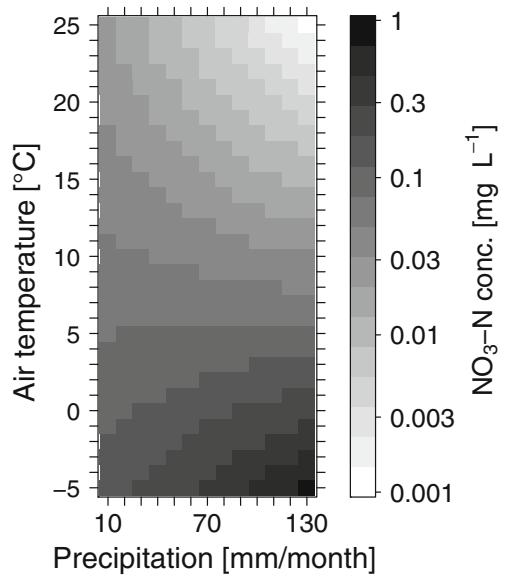

Fig. $7 \mathrm{NO}_{3}-\mathrm{N}$ concentrations in soil solution for varying monthly precipitation $(P)$ and varying monthly mean air temperature $(T)$. Constant values are as described at the beginning of "Model simulations" section

functional group richness (Table 2), although one would expect a decrease in $\mathrm{NO}_{3}-\mathrm{N}$ concentrations. As more functional groups represent a higher functional diversity and therefore more complementary resource use, $\mathrm{NO}_{3}-\mathrm{N}$ concentrations would be expected to decrease with functional group number (Hooper and Vitousek 1998; Marquard et al. 2009). But the probability that legumes are included in a mixture increases with its number of functional groups which might be the reason why the number of functional groups increased $\mathrm{NO}_{3}-\mathrm{N}$ concentrations. In previous studies, it was also found that the presence of particular functional groups, especially legumes, has more influence on $\mathrm{N}$ in soil solution and $\mathrm{N}$ leaching, respectively, than the number of functional groups (Hooper and Vitousek 1998; Oelmann et al. 2007a; Scherer-Lorenzen et al. 2003).

Functional group identity strongly affected $\mathrm{NO}_{3}-\mathrm{N}$ concentrations in soil solution (Fig. 9). If grasses were present, $\mathrm{NO}_{3}-\mathrm{N}$ concentrations were lower and if legumes were present, $\mathrm{NO}_{3}-\mathrm{N}$ concentrations were higher (see also Table 2). Moreover, $\mathrm{NO}_{3}-\mathrm{N}$ concentrations increased strongly with the percentage of legumes present in the mixture. The contributions of tall herbs and small herbs did have almost no effect on $\mathrm{NO}_{3}-\mathrm{N}$ concentrations. The associated parameter of the interaction between percentage of grasses and percentage of tall herbs $\left(a_{10}\right)$ is not significantly different from zero. These effects of presence or absence of particular functional groups, especially

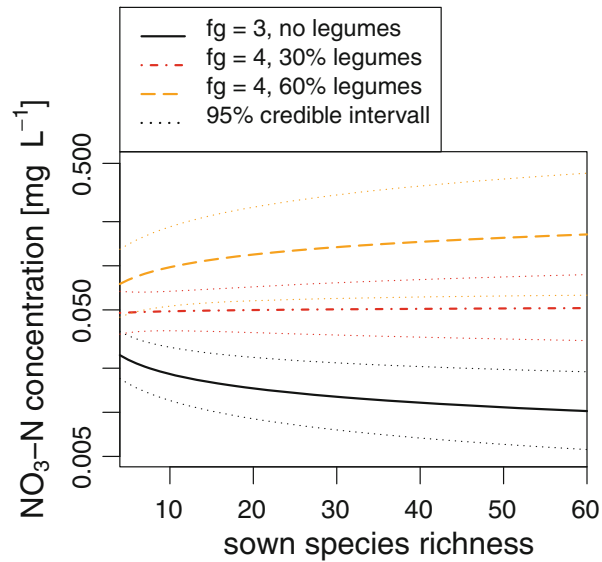

Fig. $8 \mathrm{NO}_{3}-\mathrm{N}$ concentrations in soil solution per species richness ( $s r)$ for a mixture with 3 functional groups $(f g)$ and no legumes (solid line) and two mixtures with four functional groups and $30 \%$ (dash-dotted line) and $60 \%$ (dashed line) legumes (pleg), respectively, and the $95 \%$ credible intervals (dotted lines in the respective color). Constant values are as described at the beginning of "Model simulations" section

grasses and legumes on $\mathrm{NO}_{3}-\mathrm{N}$ concentrations are in accordance with previous findings of e.g., Hooper and Vitousek (1998), Oelmann et al. (2007b), and Scherer-Lorenzen et al. (2003).

The presence of grasses generally decreased $\mathrm{NO}_{3}-\mathrm{N}$ concentrations in soil solution, but a higher percentage of grasses in mixtures without legumes reduced this decrease in $\mathrm{NO}_{3}-\mathrm{N}$ concentrations (Fig. 9). The reason for this is likely a dryness effect caused by the dense and extensive rooting system of grasses. Rosenkranz et al. (2012) also considered differences in microclimatic conditions, in particular soil water content, between species mixtures as a driver of differing insitu net ammonification rates releasing $\mathrm{NH}_{4}{ }^{+}$into soil solution, which after nitrification influence $\mathrm{NO}_{3}-\mathrm{N}$ concentrations. The difference in mean water content (0-30 cm depth) of plots without grasses minus plots with grasses was $+3.7 \mathrm{~mm}$ (calculated from ca. 15,000 measured water contents (at the 10, 20 and $30 \mathrm{~cm}$ mineral soil depth) on all 82 plots between June 2002 and January 2006, see Kreutziger 2006). Another argument for the dryness effect with increasing percentage of grasses is that the model simulated higher $\mathrm{NO}_{3}-\mathrm{N}$ concentrations under dryer soil conditions (Fig. 6).

Furthermore, interactions between spatial, climatic, and temporal variables and functional group identity were selected during model development (Table 2). 


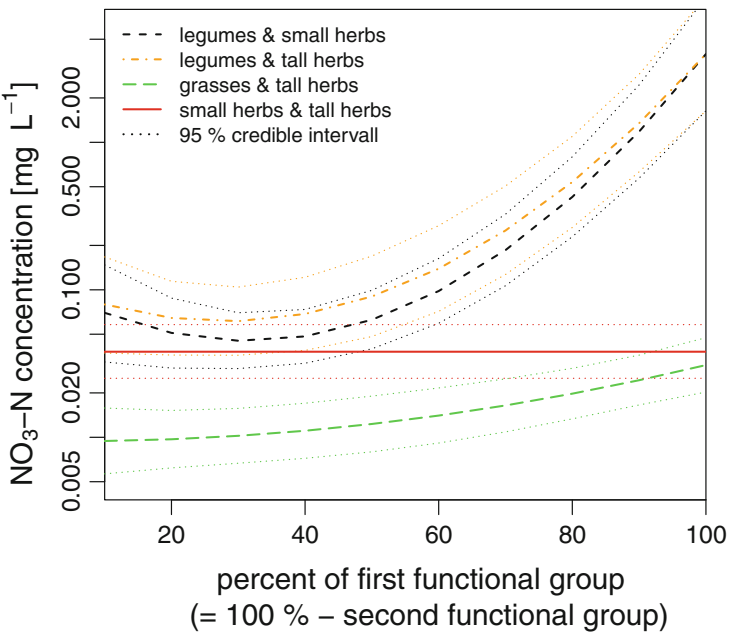

Fig. $9 \mathrm{NO}_{3}-\mathrm{N}$ concentrations in soil solution per percentage of legumes (pleg) mixed with tall herbs ( $p t h)$ or small herbs $(p s h)$, grasses (pgra) mixed with tall herbs, and small herbs mixed with tall herbs, respectively. The number of functional groups is $f g=2$, presence or absence of grasses and legumes is set according to the particular scenario and all other constant values are as described at the beginning of "Model simulations" section

These selected interactions include the interactions between percentage of grasses and year as well as the interactions between percentage of legumes and clay content, air temperature, year, and $\frac{1}{\sqrt{\text { time }}}$, respectively. Compared to the effects of the variables and interactions presented above, these interactions have a weaker influence on the $\mathrm{NO}_{3}-\mathrm{N}$ concentrations and can hardly be recognized in the model simulations. Probably, the effects of the above presented variables and interactions overlay the interactions between functional group identity and spatial, climatic, and temporal variables. The interaction between percentage of legumes and air temperature indicates that the difference in $\mathrm{NO}_{3}-\mathrm{N}$ concentrations between mixtures with a high percentage (e.g., $80 \%$ ) and a low percentage (e.g., $20 \%$ ) of legumes was highest at low air temperatures in winter $\left(T=-5{ }^{\circ} \mathrm{C}\right.$ with $2.12 \mathrm{mg} \mathrm{L}^{-1}$ difference) and almost disappeared at high temperatures in the vegetation period $\left(T=25^{\circ} \mathrm{C}\right.$ with $0.04 \mathrm{mg} \mathrm{L}^{-1}$ difference). This means that the additional $\mathrm{NO}_{3}-\mathrm{N}$, contributed by more legume species, was mostly consumed during the vegetation period leaving almost no surplus. The parameters $a$, associated to the interactions between temporal variables and percentage of grasses and legumes, respectively (Table 2), indicate that the effects of grasses and legumes on $\mathrm{NO}_{3}-\mathrm{N}$ concentrations became more important with time (year).

\section{Conclusions}

The quality of the presented Bayesian multiple regression model for monthly mean $\mathrm{NO}_{3}-\mathrm{N}$ concentrations in soil solution is acceptable because the Bayesian $p$ value was optimal with a value of 0.5 , the model predicted $\mathrm{NO}_{3}-\mathrm{N}$ concentrations in soil solution with an overall ME near 0, and the quality (e.g., measured as NSE) of our model was comparable to that of other published models for $\mathrm{NO}_{3}-\mathrm{N}$ concentrations in soil solution. Our model uses temporal, spatial, and climatic factors, plant species and functional group richness, and functional composition as explanatory variables and allows estimation of missing values simultaneously for all considered 62 plots and the time period used for model development. Such a general model for all plots has the advantage that it can be used for an overall evaluation using the experimental design which would not be the case if individual models were developed for each plot (with a presumably better fit per plot).

After accounting for the effects of the conversion from arable land to grassland, soil properties, and climate, plant diversity played an important role for $\mathrm{NO}_{3}-\mathrm{N}$ concentrations in soil solution. Species richness decreased $\mathrm{NO}_{3}-\mathrm{N}$ concentrations if no or few legumes were included in the mixture. If a threshold value of approx. $25 \%$ of legume species out of total species number was exceeded, the species richness effect reversed and increased $\mathrm{NO}_{3}-\mathrm{N}$ concentrations. This is caused by the fertilizer effect of legumes which exceeded the diversity effect. Functional group richness did not play an important role, but functional identity and composition. Within mixtures containing grasses, higher percentages of grasses in total species number increased $\mathrm{NO}_{3}-\mathrm{N}$ concentrations. Probably, the dense and extensive rooting system of grasses leads to dryer soil and therefore increases $\mathrm{NO}_{3}-\mathrm{N}$ concentrations by a concentration effect. This interaction leads us to the hypothesis that a strong underlying mechanism of species richness effects on ecosystem functioning consists of the variation in microclimatic conditions under different plant mixtures. 
Acknowledgements We thank the many people who helped with the management of the experiment and in particular the initiators, E.-D. Schulze, B. Schmid, and W. W. Weisser, as well as the scientific coordinators C. Roscher, A. Weigelt, and A. Ebeling. Thanks also to all the helpers who assisted during the weeding campaigns. We also thank Y. Kreutziger for providing soil data. The Jena Experiment is funded by the Deutsche Forschungsgemeinschaft (DFG, FOR 456 \& 1451, Wi 1601/4) and the Swiss National Science Foundation (SNSF, 200021E131195/1), with additional support from the Friedrich Schiller University Jena and the Max Planck Society. We thank the two reviewers for their valuable comments on the manuscript.

\section{References}

Cable JM, Ogle K, Lucas RW, Huxman TE, Loik ME, Smith SD, Tissue DT, Ewers BE, Pendall E, Welker JM, Charlet TN, Cleary M, Griffith A, Nowak RS, Rogers M, Steltzer H, Sullivan PF, van Gestel NC (2011) The temperature responses of soil respiration in deserts: a seven desert synthesis. Biogeochemistry 103:71-90. doi:10.1007/s10533-010-9448-z

Christian DG, Riche AB (1998) Nitrate leaching losses under Miscanthus grass planted on a silty clay loam soil. Soil Use Manag 14:131-135

Clark JS (2005) Why environmental scientists are becoming Bayesians. Ecol Lett 8:2-14. doi:10.1111/j.1461-0248. 2004.00702.x

Corre MD, Schnabel RR, Stout WL (2002) Spatial and seasonal variation of gross nitrogen transformations and microbial biomass in a northeastern US grassland. Soil Biol Biochem 34:445-457. doi:10.1016/S0038-0717(01)00198-5

Dubach M, Russelle MP (1994) Forage legume roots and nodules and their role in nitrogen transfer. Agron J 86:259-266

Ellenberg H (1996) Vegetation Mitteleuropas mit den Alpen in ökologischer, dynamischer und historischer Sicht, 5th edn. Ulmer, Stuttgart

Gelman A, Meng XL, Stern H (1996) Posterior predictive assessment of model fitness via realized discrepancies. Stat Sin 6:733-807

Gelman A, Carlin JB, Stern HS, Rubin DB (2003) Bayesian data analysis, 2nd edn. Chapman \& Hall/CRC, Boca Raton

Gu C, Riley WJ (2010) Combined effects of short term rainfall patterns and soil texture on soil nitrogen cycling - a modeling analysis. J Contam Hydrol 112:141-154. doi:10. 1016/j.jconhyd.2009.12.003

Hooper DU, Vitousek PM (1998) Effects of plant composition and diversity on nutrient cycling. Ecol Monogr 68(1):121-149. doi: $10.2307 / 2657146$

Hooper DU, Chapin FS, Ewel JJ, Hector A, Inchausti P, Lavorel S, Lawton JH, Lodge DM, Loreau M, Naeem S, Schmid B, Setälä H, Symstad AJ, Vandermeer J, Wardle DA (2005) Effects of biodiversity on ecosystem functioning: a consensus of current knowledge. Ecol Monogr 75(1):3-35. doi:10.1890/04-0922

Janssen PHM, Heuberger PSC (1995) Calibration of processoriented models. Ecol Model 83:55-66. doi:10.1016/03043800(95)00084-9

Jonard M, Legout A, Nicolas M, Dambrine E, Nys C, Ulrich E, van der Perre R, Ponette Q (2012) Deterioration of Norway spruce vitality despite a sharp decline in acid deposition: a long-term integrated perspective. Glob Change Biol 18:711-725. doi:10.1111/j.1365-2486.2011.02550.x

Kéry M (2010) Introduction to WinBUGS for ecologists: a Bayesian approach to regression, ANOVA, mixed models and related analyses, 1st edn. Academic Press, Burlington

Kluge G, Müller-Westermeier G (2000) Das Klima ausgewählter Orte der Bundesrepublik Deutschland: Jena, Berichte des Deutschen Wetterdienstes, vol 213. Deutscher Wetterdienst, Offenbach am Main, Germany

Kreutziger Y (2006) Rückkopplungseffekte verschieden diverser Grünlandökosysteme auf die Komponenten des Bodenwasserhaushalts an einem Auestandort der Saale. Dissertation, Friedrich Schiller University Jena, Jena

Kristensen HL, Gundersen P, Callesen I, Reinds GJ (2004) Throughfall nitrogen deposition has different impacts on soil solution nitrate concentration in European coniferous and deciduous forests. Ecosystems 7:180-192. doi:10. 1007/s10021-003-0216-y

Li C, Farahbakhshazad N, Jaynes DB, Dinnes DL, Salas W, McLaughlin D (2006) Modeling nitrate leaching with a biogeochemical model modified based on observations in a row-crop field in Iowa. Ecol Model 196:116-130. doi:10. 1016/j.ecolmodel.2006.02.007

Li Y, White R, Chen D, Zhang J, Li B, Zhang Y, Huang Y, Edis R (2007) A spatially referenced water and nitrogen management model (WNMM) for (irrigated) intensive cropping systems in the North China Plain. Ecol Model 203:395-423. doi:10.1016/j.ecolmodel.2006.12.011

Loreau M (1998) Biodiversity and ecosystem functioning: a mechanistic model. Proc Natl Acad Sci USA 95:5632-5636. doi:10.1073/pnas.95.10.5632

Loreau M, Naeem S, Inchausti P, Bengtsson J, Grime JP, Hector A, Hooper DU, Huston MA, Raffaelli D, Schmid B, Tilman D, Wardle DA (2001) Biodiversity and ecosystem functioning: current knowledge and future challenges. Science 294:804-808. doi:10.1126/science.1064088

Lunn D, Spiegelhalter D, Thomas A, Best N (2009) The BUGS project: evolution, critique and future directions. Stat Med 28:3049-3067. doi:10.1002/sim.3680

Majumdar A, Kaye J, Gries C, Hope D, Grimm N (2008) Hierarchical spatial modeling and prediction of multiple soil nutrients and carbon concentrations. Commun Stat Simul Comput 37:434-453. doi:10.1080/03610910701 792588

Marquard E, Weigelt A, Temperton VM, Roscher C, Schumacher J, Buchmann N, Fischer M, Weisser WW, Schmid B (2009) Plant species richness and functional composition drive overyielding in a six-year grassland experiment. Ecology 90:3290-3302. doi:10.1890/09-0069.1

Meng XL (1994) Posterior predictive p-values. Ann Stat 22:1142-1160. doi:10.1214/aos/1176325622

Nash JE, Sutcliffe JV (1970) River flow forecasting through conceptual models part 1 - a discussion of principles. J Hydrol 10:282-290. doi:10.1016/0022-1694(70)90255-6

Niklaus PA, Kandeler E, Leadley PW, Schmid B, Tscherko D, Körner C (2001) A link between plant diversity, elevated $\mathrm{CO}_{2}$ and soil nitrate. Oecologia 127:540-548. doi:10.1007/ s004420000612

Ntzoufras I (2009) Bayesian modeling using WinBUGS. Wiley, Hoboken 
Oelmann Y, Kreutziger Y, Bol R, Wilcke W (2007a) Nitrate leaching in soil: tracing the $\mathrm{NO}_{3}{ }^{-}$sources with the help of stable N and O isotopes. Soil Biol Biochem 39:3024-3033. doi:10.1016/j.soilbio.2007.05.036

Oelmann Y, Kreutziger Y, Temperton VM, Buchmann N, Roscher C, Schumacher J, Schulze ED, Weisser WW, Wilcke W (2007b) Nitrogen and phosphorus budgets in experimental grasslands of variable diversity. J Environ Qual 36:396-407. doi:10.2134/jeq2006.0217

Oelmann Y, Wilcke W, Temperton VM, Buchmann N, Roscher C, Schumacher J, Schulze ED, Weisser WW (2007c) Soil and plant nitrogen pools as related to plant diversity in an experimental grassland. Soil Sci Soc Am J 71:720-729. doi:10.2136/sssaj2006.0205

Oleson JJ, Hope D, Gries C, Kaye J (2006) Estimating soil properties in heterogeneous land-use patches: a Bayesian approach. Environmetrics 17:517-525. doi:10.1002/env. 789

Pedersen A, Petersen B, Eriksen J, Hansen S, Jensen L (2007) A model simulation analysis of soil nitrate concentrationsdoes soil organic matter pool structure or catch crop growth parameters matter most? Ecol Model 205:209-220. doi:10. 1016/j.ecolmodel.2007.02.016

Proulx R, Wirth C, Voigt W, Weigelt A, Roscher C, Attinger S, Baade J, Barnard RL, Buchmann N, Buscot F, Eisenhauer N, Fischer M, Gleixner G, Halle S, Hildebrandt A, Kowalski E, Kuu A, Lange M, Milcu A, Niklaus PA, Oelmann Y, Rosenkranz S, Sabais A, Scherber C, Scherer-Lorenzen M, Scheu S, Schulze ED, Schumacher J, Schwichtenberg G, Soussana JF, Temperton VM, Weisser WW, Wilcke W, Schmid B (2010) Diversity promotes temporal stability across levels of ecosystem organization in experimental grasslands. PLOS ONE 5:e13382. doi:10.1371/journal. pone. 0013382

R Development Core Team (2006) R: a language and environment for statistical computing. R Foundation for Statistical Computing, Vienna, Austria, url: http://www.R-project.org

Riley WJ, Matson PA (2000) NLOSS: a mechanistic model of denitrified $\mathrm{N}_{2} \mathrm{O}$ and $\mathrm{N}_{2}$ evolution from soil. Soil Sci 165:237-249. doi:10.1097/00010694-200003000-00006

Roscher C, Schumacher J, Baade J, Wilcke W, Gleixner G, Weisser WW (2004) The role of biodiversity for element cycling and trophic interactions: an experimental approach in a grassland community. Basic Appl Ecol 5:107-121. doi:10.1078/1439-1791-00216

Rosenkranz S, Wilcke W, Eisenhauer N, Oelmann Y (2012) Net ammonification as influenced by plant diversity in experimental grassland. Soil Biol Biochem 48:78-87. doi:10. 1016/j.soilbio.2012.01.008

Sala OE, Chapin FS, Armesto JJ, Berlow E, Bloomfield J, Dirzo R, Huber-Sanwald E, Huenneke LF, Jackson RB, Kinzig A, Leemans R, Lodge DM, Mooney HA, Oesterheld M,
Poff NL, Sykes MT, Walker BH, Walker M, Wall DH (2000) Global biodiversity scenarios for the year 2100 . Science 287:1770-1774. doi:10.1126/science.287.5459. 1770

Scherer-Lorenzen M, Palmborg C, Prinz A, Schulze ED (2003) The role of plant diversity and composition for nitrate leaching in grasslands. Ecology 84(6):1539-1552. doi: 10.1890/0012-9658(2003)084[1539:TROPDA]2.0.CO;2

Schilling KE, Spooner J (2006) Effects of watershed-scale land use change on stream nitrate concentrations. J Environ Qual 35:2132-2145. doi:10.2134/jeq2006.0157

Schimel JP, Bennett J (2004) Nitrogen mineralization: challenges of a changing paradigm. Ecology 85(3):591-602. doi: $10.1890 / 03-8002$

Spehn EM, Joshi J, Schmid B, Diemer M, Korner C (2000) Above-ground resource use increases with plant species richness in experimental grassland ecosystems. Funct Ecol 14(3):326-337

Spiegelhalter DJ, Best NG, Carlin BP, van der Linde A (2002) Bayesian measures of model complexity and fit. J R Stat Soc B Stat Methodol 64:583-639. doi:10.1111/1467-9868. 00353

Steinbeiss S, Beßler H, Engels C, Temperton VM, Buchmann N, Roscher C, Kreutziger Y, Baade J, Habekost M, Gleixner G (2008) Plant diversity positively affects short-term soil carbon storage in experimental grasslands. Glob Change Biol 14:2937-2949. doi:10.1111/j.1365-2486.2008.01697.x

Stevenson FJ, Cole MA (1999) Cycles of soil: carbon, nitrogen, phosphorus, sulfur, micronutrients, 2nd edn. Wiley, New York

Tilman D, Wedin D, Knops J (1996) Productivity and sustainability influenced by biodiversity in grassland ecosystems. Nature 379:718-720. doi:10.1038/379718a0

Tilman D, Knops J, Wedin D, Reich P, Ritchie M, Siemann E (1997) The influence of functional diversity and composition on ecosystem processes. Science 277(5330):1300-1302. doi:10.1126/science.277.5330.1300

van der Laan M, Stirzaker RJ, Annandale JG, Bristow KL, du Preez CC (2010) Monitoring and modelling draining and resident soil water nitrate concentrations to estimate leaching losses. Agric Water Manag 97:1779-1786. doi:10.1016/j.agwat.2010.06.012

van Schöll L, van Dam AM, Leffelaar P (1997) Mineralisation of nitrogen from an incorporated catch crop at low temperatures: experiment and simulation. Plant Soil 188:211-219. doi:10.1023/A:1004255102840

Weigelt A, Marquard E, Temperton VM, Roscher C, Scherber C, Mwangi PN, von Felten S, Buchmann N, Schmid B, Schulze ED, Weisser WW (2010) The Jena Experiment: six years of data from a grassland biodiversity experiment. Ecol Freshw Fish 91:929 